\title{
Activating the Role of Digital Volunteering in Early Detection of Unhealthy Behavior on University Campus in the Era of Covid 19 Crisis
}

\section{Razan Alarnous}

Princess Nourah bint Abdulrahman University

Aida Albasalah

Princess Nourah bint Abdulrahman University

Samar Alshawwa ( $\nabla$ samarzuhair@yahoo.com)

Princess Nourah bint Abdulrahman University https://orcid.org/0000-0001-9232-7956

\section{Research}

Keywords: communication, digital volunteering, disaster management, social media,technology, unhealthy behavior.

Posted Date: July 22nd, 2021

DOI: https://doi.org/10.21203/rs.3.rs-729709/v1

License: () (i) This work is licensed under a Creative Commons Attribution 4.0 International License. Read Full License 


\section{Abstract}

\section{Background}

The current study aims to identify unhealthy behaviors among university students, establish means of detecting them as well as identify obstacles to digital volunteering and also explore the relationship between volunteer preferred style of volunteering and the obstacles to volunteering.

\section{Methods}

Data for the study was gathered by administering unstructured, anonymous questionnaire to 207 female university students and staff. The survey design included questions about socio-demographic characteristics, views on different facets of volunteering, unhealthy behaviors and correlation between volunteering and unhealthy behaviors.

\section{Results}

The result revealed unhealthy behavior detected by the respondents (51.7\%). Twenty-eight (13.5\%) of the 207 respondents reported to use social media in detecting women with offending behavior. The value of Pearson's $\mathrm{R}$ is 0.245 ; thus is considered a weak or no correlation. There is hence no correlation between how respondents preferred volunteer work and the obstacle to volunteering. There is no much of difference in the obstacles to volunteering faced by respondents despite their preferred style of volunteering.

\section{Conclusion}

The findings reveal that digital volunteering is effectively gaining ground in detection and management of unhealthy behaviors among university students. Much more could be achieved through digital volunteering if more awareness is created and volunteering programs are designed to be more interesting and less time consuming to give more students the opportunity to participate.

\section{Background}

The outlook of volunteering is gradually changing in the 21 st century in manners that bring significant problems as well as opportunities for managing disaster. Particularly, shifts in the pattern of paid jobs, values and lifestyles, and latest technology, has resulted in a decrease in 'conventional', highcommitment, long-term volunteering and an increase in more vast, flexible and periodic patterns of volunteering. Rising adulthood as a phase of life, to which higher education students belong, matches a phase of personality development and education, in the physical, mental, sexual, family, emotional and communal domains. Scientific facts show an elevated occurrence of unhealthy behaviors among university students which have a tendency to persevere all through life and to have a significant enduring brunt on their health and total well-being. According to [1, 2], "the commonest sources of information about COVID-19 for university students are the media $[3,4]$ and social networks". Followed by these sources of information were the World Health Organization, television, the Ministry of Health, friends and the Internet [1, 2]. This facet reveals the significance of the internet in conducting campaigns on health education targeted at students of higher education [3,5], namely the various national websites [6] and international health authorities [7]. Certified announcements published by governments [2] were also part of the chief sources of information for students of university. The research done by Yang and colleagues [2] revealed that ninety-five percent of the students studied got awareness about COVID-19 in press releases by government and expressed credence in the information.

Rising adulthood as a phase of life, to which students of higher education belong, matches a phase of personality development and education, in the corporal, mental, family, sexual, emotional and communal domains [8]. Nevertheless, scientific evidence shows an elevated occurrence of unhealthy behaviors among students of universities [9] which have a tendency to persevere all through life as well as to possess a significant enduring impact on their health and total well-being [10]. Furthermore, students of university should be considered emerging advancement agents, hinged on the idea that they have advantaged knowledge owing to their educational background and, as a result, possess the ability to manipulate a population's health. This can be exercised either via their personal decisions, via theoretical prospective vocations which entail responsibilities in creating health guidelines or decision making procedures about them $[11,12,13]$. These rising adults are liable for opening a variety of precautionary options to the public based on communication of knowledge and the implementation of preventive behaviors regarding possible communicable diseases in this respect.

Digital volunteering offers immense potentials for disaster management in the aspect of disaster announcement, as well as challenges and risks [14, 15]. Major challenges arise from strains between the command - control tradition in emergency management and the very flat and auto-organizing character of several digital volunteering. Research points out that command - control configurations "do not easily adapt to the expanding data-generating and -seeking activities by the public" [16]. Certainly, digital volunteering forms a prospective force for decentralizing and dispensing influence within emergency management. It entails not merely a shift in technology but as well a course of quick delegation of control. With enormously little obstacles to access, several new applicants are emerging in the fields of emergency and disaster response [17].

Latest technologies have therefore opened up "virtual spaces" for volunteer activism and participation that give an authority podium for people "to make their voices heard, to coordinate activities across the globe and to mobilize public opinion" [18]. In the perspective of disaster, digital volunteers are able generate and use the virtual spaces as podiums to manage unofficial rejoinders that may or may not be incorporated with and corresponding to the official emergency management system.

The enormous impact of novel communications technology is another revolution that has extensive inferences for the manner in which unofficial, postdisaster volunteering come about, and incontestably all disaster volunteering. The United Nations Volunteer program states that "technological developments 
are opening up spaces for people to volunteer in ways that have no parallel in history" [19]. Electronic or digital volunteering "has eliminated the need for volunteerism to be tied to definite times and locations. Thus, it greatly increases the freedom and flexibility of volunteer engagement and complements the outreach and impact of volunteers serving in situ" [19]. The burst in mobile technology and social media in particular has lowered the information and communication impediments to partaking in disaster response and recovery [17]. Therefore, it has facilitated a development in "digitally-enabled volunteering" due disasters that occur both digitally and physically, or, as is frequently the case, in interaction [20, 21]. Meier (2012) [22]; Zook et al. (2010) [23] stated that "The trend of digital volunteering in particular has earned noteworthy research attention since the immense response of digital volunteers to the 2010 Haiti earthquake". This was a turning point event that paved way for "digital humanitarianism" that is really global in reach [17]. To a large extent, online volunteers have been reported to be more successful than conventional government organizations at organizing, collating, managing and disseminating the "data deluge" that is prompted by disasters in the Internet age in close to real time to increase conditional awareness [24]. According to Haworth and Bruce (2015), a key strength of digital volunteering arises from the huge capability of the internet to facilitate crowd-sourcing, mostly for volunteered geographic information (VGI). VGI "involves the sharing and mapping of spatial data through voluntary information gathered by the general public" [15], and it is especially influential for disaster circumstances. This is progressively more recognized by well-known actors. Conspicuously, the Information Services Section (ISS) of the United Nations Office for the Coordination of Humanitarian Affairs (OCHA) started a digital volunteering network-The Standby Taskforce-to create live, crowdsourced crisis maps for the 2011 Libyan revolution that was afterwards used by humanitarian organizations to coordinate their relief activities [22].

Unhealthy behavior refers to any action an individual takes with intensity or at a rate that raises risk of injury or disease [25]. It might sum up into a risky way of life which influences emotions, cognitive performance, and the general value of life. A great deal of the sicknesses and deaths result from individuals' behavioral styles; polluted environment, poverty or psychological affairs, [26]. A research carried out by Poortinga (2007) established that many university students binge drink, smoke tobacco, don't eat sufficient fruits and vegetables and do not exercise enough [27] (Danaei, Ding and Mozaffarian, 2009) identified five groups of behaviors that have been found consistently to associate with increased sickness and death. The list includes "low levels of physical activity and high levels of sedentary activity; eating a diet high in fat and sodium, calories, and low in nutrients; smoking cigarettes; substances abuse including alcohol, illicit and remedy drugs, and risky sexual behaviors" [28]. Latest advancements in brain research have established a precarious connection between youths and unhealthy behaviors, expounding the reality that adolescence is the significant stage of risk for both unhealthy behaviors and its outcome. Adults are less susceptible to unhealthy behavior than adolescents because the sections of the brain that control decision making, judgment, impulse control and emotion are not yet completely developed in adolescents. Thus, teens are more likely to take risks than adults, including engaging in dangerous behaviors and experimenting with drug abuse [29]. The chances of undertaking several unhealthy behaviors increase over the process of growth, principally during the teenage years. Through sexual risk physical risks and experimentation with substances, some adolescents attain unhealthy behaviors and peers that endure and dampen the cultivation of other self-regulatory attitudes. Notwithstanding efforts made towards health promotion, young adults continue to practice high levels of unhealthy behaviors as established by (Das and Horton, 2012) [30]. It is essential to understand unhealthy behaviors among youths, as early detection of such behaviors and their subsequent modifications can significantly improve every aspect of health, and reduce the risk of chronic diseases later in life [31].

The objective of the study is to identify unhealthy behavior among university students; establish the means of detection of unhealthy behavior; identify the obstacles to volunteering; and obtaining the relationship between volunteer preferred style of volunteering and the obstacles to volunteering.

\section{Methods}

In order to gather data for the study, an anonymous structured questionnaire was administered to both students and staff at Princess Nourah bint Abdulrahman University, Riyadh, Saudi Arabia. 207 validly filled questionnaires were retrieved. The respondents were all females within the age range of 18 and above.

The questionnaire for this study was developed by the authors, it was in Arabic language and never been used before.

The survey design included questions about socio-demographic characteristics, views on different facets of volunteering, unhealthy behaviors and correlation between volunteering and unhealthy behaviors.

The data gathered was subjected to Statistical Package for Social Science (SPSS) 2020. Descriptive statistics were used to report the percentages for definite variables while mean values with standard deviations were used to report continuous variables. Missing data were omitted on a basis analysis-by-analysis and valid percentages were reported. The data was also subjected to correlation analysis to determine the relationship between volunteer preferred style of volunteering and the obstacles to volunteering.

\section{Results}

The demographic characteristics of the respondents revealed age ranging from 18 years to above 35 years. It is not surprising that the marital status of most $(92.8 \%)$ of the respondents were single as the sample population comprised mainly students. Table 1 
Table 1

Social demographic characteristics of the respondents

\begin{tabular}{|c|c|c|}
\hline Variable & Frequency & Percent \\
\hline \multicolumn{3}{|l|}{ Age } \\
\hline 18 to $23 y r s$ & 169 & 81.6 \\
\hline 24 to $28 y r s$ & 31 & 15.0 \\
\hline 29 to $34 \mathrm{yrs}$ & 2 & 1.0 \\
\hline $35 y r s$ and above & 5 & 2.4 \\
\hline Total & 207 & 100.0 \\
\hline \multicolumn{3}{|l|}{ University_Education_Level } \\
\hline 1st Year & 4 & 1.9 \\
\hline 2nd Year & 54 & 26.1 \\
\hline 3rd Year & 14 & 6.8 \\
\hline 4th Year & 16 & 7.7 \\
\hline After \$th Year & 109 & 52.7 \\
\hline Postgraduate & 10 & 4.8 \\
\hline Total & 207 & 100.0 \\
\hline \multicolumn{3}{|l|}{ Marital_Status } \\
\hline Single & 192 & 92.8 \\
\hline Married & 14 & 6.8 \\
\hline Divorced & 1 & .5 \\
\hline Total & 207 & 100.0 \\
\hline \multicolumn{3}{|l|}{ Occupation } \\
\hline Student & 178 & 86.0 \\
\hline Student + Self-employed & 6 & 2.9 \\
\hline Self Employed & 4 & 1.9 \\
\hline Partly Employee & 19 & 9.2 \\
\hline Total & 207 & 100.0 \\
\hline \multicolumn{3}{|c|}{ Monthly income of the Family } \\
\hline Less than SR 3,000 & 36 & 17.4 \\
\hline 3,000 to 3,499 riyals & 22 & 10.6 \\
\hline 3,500 to 4,900 riyals & 11 & 5.3 \\
\hline 5,000 to 6,499 riyals & 4 & 1.9 \\
\hline 6,500 to 7,999 riyals & 6 & 2.9 \\
\hline 8,000 to 10,000 riyals & 19 & 9.2 \\
\hline Above 10,000 riyals & 67 & 32.4 \\
\hline Undefined/Unspecified & 42 & 20.3 \\
\hline Total & 207 & 100.0 \\
\hline
\end{tabular}

Regarding the source of income of the respondents, most (42\%) of the respondents had their source of income from university reward; this is followed by $25.1 \%$ of the respondents whose source personal income were from all of university reward, parents and grandparents. Others had their personal source of income ranging from monthly salary, husband, internship, donation and alms, business, social security, charities and other sources as listed in the Table 2 below. 
Table 2

Source of personal income of respondents

\begin{tabular}{|lll|}
\hline Source of Personal Income & Frequency & Percent \\
\hline No Job & 1 & 0.5 \\
\hline University Reward & 87 & 42.0 \\
\hline University Reward/Parents/GrandParents & 52 & 25.1 \\
\hline Parents/Grandparents & 12 & 5.8 \\
\hline Donation and Alms & 1 & 0.5 \\
\hline Monthly Salary & 2 & 1.0 \\
\hline Position after the University & 18 & 8.7 \\
\hline Position after the University/University Reward/Parents/Grandparents & 12 & 5.8 \\
\hline Husband & 6 & 2.9 \\
\hline University Reward/Parents/GrandParents/Social Security & 2 & 1.0 \\
\hline Position after the University/University Reward/Charity/Social Security & 2 & 1.0 \\
\hline Internship & 6 & 2.9 \\
\hline University/Social Security & 2 & 1.0 \\
\hline Position after the University/University Reward/Husband & 1 & 0.5 \\
\hline Position after the University/Husband & 1 & 0.5 \\
\hline University Reward/Business & 1 & 0.5 \\
\hline Position after the University/Charity/Social Security & 1 & 0.5 \\
\hline Total & 100.0 \\
\hline
\end{tabular}

With regards to the mode of volunteering, it seems that the pandemic of covide 19 affected the expected voluntary behaviors. Results showed that $30 \%$ of the respondents prefer to volunteer though groups. This percentage was expected to be more but due to the pandemic of Covid 19 it was less since students cannot meet and work in groups. The results also show that nowadays most of the respondents prefer electronic volunteering, due to the limitation of gathering and outdoors activities because of Covid 19. (Table 3).

Table 3

How do you prefer volunteering

\begin{tabular}{|lll|}
\hline Variable & Frequency & Percent \\
\hline In Group & 63 & 30.4 \\
\hline Individual & 10 & 4.8 \\
\hline group (In hospital) & 37 & 17.9 \\
\hline Individual/Group & 10 & 4.8 \\
\hline Individual/Group/Electronic & 21 & 10.1 \\
\hline Individual/Group/Electronic/Cafe/Coffee shop. & 39 & 18.8 \\
\hline Individual/Group/Hospital & 16 & 7.7 \\
\hline Group/Electronic & 9 & 4.3 \\
\hline Individual/Electronic & 2 & 1.0 \\
\hline Total & $\mathbf{2 0 7}$ & $\mathbf{1 0 0 . 0}$ \\
\hline
\end{tabular}

Lack of time constitutes the greatest obstacle to digital volunteering, representing almost half (48.8\%) of the entire data while lack of conviction/interest/time represent constitute the least obstacle (0.5\%). Other factors that hinder digital volunteering as shown by the table include Lack of time + weak interest $(15.0 \%)$, lack of awareness and culture (7.2\%). Table 4. 
Table 4

Obstacles to volunteering

\begin{tabular}{|llll|}
\hline Obstacles to volunteering (Variables) & Frequency & Percent & Cumulative Percent \\
\hline Lack of time & 101 & 48.8 & 48.8 \\
\hline Lack of awareness and culture & 15 & 7.2 & 56.0 \\
\hline Lack of Interest & 11 & 5.3 & 61.4 \\
\hline Lack of time+ weak interest & 31 & 15.0 & 76.3 \\
\hline Lack of time + lack of conviction & 8 & 3.9 & 80.2 \\
\hline Lack of time/conviction/awareness & 16 & 7.7 & 87.9 \\
\hline Lack of conviction/interest/time/awreness & 4 & 1.9 & 89.9 \\
\hline Lack of time/conviction/awareness/culture/interest & 11 & 5.3 & 95.2 \\
\hline Lack of conviction & 3 & 1.4 & 96.6 \\
\hline Lack of conviction/interest/time & 1 & 0.5 & 97.1 \\
\hline Lack of awareness/culture/Interest & 3 & 1.4 & 98.6 \\
\hline Lack of Time and Transport & 3 & 1.4 & 100.0 \\
\hline Total & $\mathbf{2 0 7}$ & $\mathbf{1 0 0 . 0}$ & \\
\hline
\end{tabular}

University administration has a positive role in the development of volunteering work. it is also observed that volunteering positively affect university volunteers. This is seen as most of the respondents agreed that volunteering enabled them develop sufficient interest to strive to continually update their information as development in the field persists. Most respondents reported enhanced communication skills; other positive roles include improved ability to tackle problems, and development of basic skills in the use of technology as shown in Table 5. 
Table 5

The effect of volunteering on university volunteers

\begin{tabular}{|c|c|c|}
\hline Variable & Frequency & Percentage \\
\hline \multicolumn{3}{|c|}{ University Administration has a positive role in the development of volunteering work } \\
\hline Strongly Agree & 80 & 38.6 \\
\hline Agree & 84 & 40.6 \\
\hline Neutral & 38 & 18.4 \\
\hline Disagree & 3 & 1.4 \\
\hline Strongly Disagree & 2 & 1.0 \\
\hline Total & 207 & 100.0 \\
\hline \multicolumn{3}{|c|}{ Volunteering triggered me to update my information as development in the field } \\
\hline Strongly Agree & 71 & 34.3 \\
\hline Agree & 78 & 37.7 \\
\hline Neutral & 36 & 17.4 \\
\hline Disagree & 16 & 7.7 \\
\hline Strongly Disagree & 6 & 2.9 \\
\hline Total & 207 & 100.0 \\
\hline \multicolumn{3}{|c|}{ Volunteer work improved my ability to investigate and solve problem } \\
\hline Strongly Agree & 61 & 29.5 \\
\hline Agree & 65 & 31.4 \\
\hline Neutral & 44 & 21.3 \\
\hline Disagree & 29 & 14.0 \\
\hline Strongly Disagree & 8 & 3.9 \\
\hline Total & 207 & 100.0 \\
\hline \multicolumn{3}{|c|}{ Volunteer work improved my communication skills } \\
\hline Strongly Agree & 87 & 42.0 \\
\hline Agree & 74 & 35.7 \\
\hline Neutral & 41 & 19.8 \\
\hline Disagree & 5 & 2.4 \\
\hline Strongly Disagree & 0 & 0 \\
\hline Total & 207 & 100.0 \\
\hline \multicolumn{3}{|c|}{ Volunteer work helped me develop basic skills in the use of technology } \\
\hline Strongly Agree & 67 & 32.4 \\
\hline Agree & 84 & 40.6 \\
\hline Neutral & 44 & 21.3 \\
\hline Disagree & 9 & 4.3 \\
\hline Strongly Disagree & 3 & 1.4 \\
\hline Total & 207 & 100.0 \\
\hline
\end{tabular}

From Table 6 below, only 28 (13.5\%) of the 207 respondents reported to use social media in detecting women with offending behavior.

Table 6

Social media in detecting women with unhealthy behavior

\begin{tabular}{|c|c|c|c|c|c|}
\hline & & Frequency & Percent & Valid Percent & Cumulative Percent \\
\hline \multirow[t]{3}{*}{ Valid } & YES & 28 & 13.5 & 13.5 & 13.5 \\
\hline & NO & 179 & 86.5 & 86.5 & 100.0 \\
\hline & Total & 207 & 100.0 & 100.0 & \\
\hline
\end{tabular}

Page $7 / 14$ 
When considering the most widely used methods of communication, Twitter is the most widely used method of communication as $50 \%$ (14) of the respondents (28) make use of it. This was followed by both Twitter \& Instagram and Twitter, Snapchat, Phone calls, YouTube, Linkedln, Whatsapp \& Telegram which were utilized by $3(1.4 \%)$ of the respondents each. $2(1 \%)$ of the respondents use snapchat as a medium of communication, another 2 (\%) of them utilize Twitter coupled with surfing the web; $1(0.5 \%)$ of the respondents browse the web only as a means of communication. Table 7 and Fig. 1 .

Table 7

The most widely used method of communication

\begin{tabular}{|c|c|c|c|c|c|}
\hline \multirow[t]{2}{*}{ How do you prefer volunteering? } & \multicolumn{5}{|c|}{ The most widely used method of communication } \\
\hline & SnapChat & Twitter & SnapChat/Twitter & Twitter/Snapchat/Instagram & $\begin{array}{l}\text { Twitter/Snapchat/Phone } \\
\text { calls/YouTube/Linkedln/Whatsap! }\end{array}$ \\
\hline In Group & 0 & 10 & 1 & 0 & 0 \\
\hline Individual & 0 & 0 & 0 & 0 & 1 \\
\hline group (In hospital) & 0 & 1 & 0 & 1 & 0 \\
\hline Individual/Group & 0 & 0 & 1 & 0 & 0 \\
\hline Individual/Group/Electronic/h. & 2 & 0 & 0 & 0 & 0 \\
\hline $\begin{array}{l}\text { Individual/Group/Electronic/Cafe/Coffee } \\
\text { shop. }\end{array}$ & 0 & 3 & 0 & 0 & 2 \\
\hline Total & 2 & 14 & 2 & 1 & 3 \\
\hline
\end{tabular}

Table 8 shows the mean and standard deviation of Reasons for participation and assistance mechanism to detect the unhealthy behavior in the university.

Table 8

Reasons for participation and assistance mechanism to detect the unhealthy behavior in the university

\begin{tabular}{|llllllllll|}
\hline & CK & CL & CM & CN & CO & CP & CR & CT & CU \\
\hline N Valid & 164 & 163 & 162 & 163 & 164 & 163 & 163 & 162 & 163 \\
\cline { 4 - 5 } & 43 & 44 & 45 & 44 & 43 & 44 & 44 & 45 & 44 \\
\hline Mean & 2.9329 & 3.0000 & 2.7531 & 2.8650 & 2.4695 & 2.5153 & 2.7853 & 2.4198 & 2.5276 \\
\hline Std. Deviation & 1.24896 & 1.20185 & 1.08096 & 1.12500 & .99338 & 1.07356 & 1.08720 & 1.01375 & 1.05592 \\
\hline
\end{tabular}

Key: $\mathrm{CK}=$ My exposure to blackmail by those who do the unhealthy behavior and my rejection of the behavior prompted me to participate in monitoring the offending behavior. $\mathrm{CL}=$ my ability to hack the websites, and by influencing others helped me to monitor the unhealthy behavior. $\mathrm{CM}=$ advertisement and invitations in the university led me to participate in reducing unhealthy behavior. $\mathrm{CN}=$ my friends volunteer in reducing unhealthy behavior encouraging me with their experiences, to experiment with monitoring the unhealthy behavior. $\mathrm{CO}=$ my values and principles of religion made me motivated to participate in the monitoring of the unhealthy behavior for the satisfaction of God. CP = my knowledge of the types of offending behavior and harm to the individual and society encouraged me to fight. CR = Peer indifference to the matter, out of fear, irresponsibility, or distance from problems was frustrating me on one hand and encouraging me on the other hand to uncover unhealthy behavior and follow-up and continue doing so. CT = My sense of security in terms of ease of tracking and lack of regulatory laws made it easy for me to contribute to uncovering the offending behavior. $\mathrm{CU}=\mathrm{Guidance}$ and counseling by professors, clubs, volunteers and the Community Service Agency raised my spirits, so I made the unhealthy behavior and detection of it my priority.

Table 9 below, shows that 37 (17.9\%) of the respondents indicated that Attack on Others and Properties is the most prevalent unhealthy behavior found among university students; this is followed by Bullying/Insults/Verbal abuse and Bullying (13.5\%) and (8.7\%) respectively. 
Table 9

Unhealthy behavior detected by respondents

\begin{tabular}{|c|c|c|c|}
\hline \multicolumn{2}{|c|}{ Unhealthy Behaviors } & \multirow{2}{*}{$\begin{array}{l}\text { Frequency } \\
7\end{array}$} & \multirow{2}{*}{$\begin{array}{l}\text { Percent } \\
3.4\end{array}$} \\
\hline Valid & Smoking/Drug Abuse & & \\
\hline & Sexual Abnormalities & 2 & 1.0 \\
\hline & Bullying/Insults/Verbal abuse & 28 & 13.5 \\
\hline & Theft & 6 & 2.9 \\
\hline & Attack on Others and Properties & 37 & 17.9 \\
\hline & Bullying & 18 & 8.7 \\
\hline & Smoking and Bullying & 2 & 1.0 \\
\hline & Sexual Abnormalities and Bullying & 1 & 0.5 \\
\hline & Sexual Abnormalities/Extortion/Bullying/Insults/Verbal Abuse & 4 & 1.9 \\
\hline & Inappropriate disposal of waste/refuse & 1 & 0.5 \\
\hline & Drug Abuse/Wrong Use of Medication & 1 & 00.5 \\
\hline & Total & 107 & 51.7 \\
\hline Missing & System & 100 & 48.3 \\
\hline Total & & 207 & 100.0 \\
\hline
\end{tabular}

Most of the respondents (70) who do volunteer work do it in the Princess Nourah University and have revealed to have helped detect unhealthy behavior among women. Others carry out their volunteering work at Community development association (11), charitable association (5), outside the university (10), both within and outside the university (21), the only respondent who carry out volunteer work electronically have not helped to detect any kind of unhealthy behavior. Table 10

Table 10

Detection of unhealthy behavior

\begin{tabular}{|c|c|c|c|c|c|}
\hline & & \multicolumn{3}{|c|}{$\begin{array}{l}\text { Have you ever helped to detect any kind of unhealthy } \\
\text { behavior? }\end{array}$} & \multirow[t]{2}{*}{ Total } \\
\hline & & Did not reveal & Yes & No & \\
\hline \multirow{7}{*}{$\begin{array}{l}\text { Where do you do your volunteer } \\
\text { work? }\end{array}$} & None & 2 & 31 & 24 & 57 \\
\hline & $\begin{array}{l}\text { Princess Nourah University/Hospital/Ministry of } \\
\text { Health }\end{array}$ & 1 & 31 & 38 & 70 \\
\hline & Community Development Association & 0 & 11 & 3 & 14 \\
\hline & Charitable Association & 0 & 5 & 8 & 13 \\
\hline & Outside the University & 0 & 10 & 5 & 15 \\
\hline & Both Within and Outside the University & 1 & 21 & 15 & 37 \\
\hline & Electronically & 0 & 0 & 1 & 1 \\
\hline Total & & 4 & 109 & 94 & 207 \\
\hline
\end{tabular}

As shown in Table 11, the value of Pearson's $\mathrm{R}$ is 0.245 ; thus is considered a weak or no correlation. There is hence no correlation between how respondents preferred volunteer work and the obstacle to volunteering. There is no much of difference in the obstacles to volunteering faced by respondents despite their preferred style of volunteering. 
Table 11

Correlation between how respondents prefer volunteer work and the obstacle to volunteering

\begin{tabular}{|c|c|c|c|c|c|}
\hline \multicolumn{6}{|c|}{ Symmetric Measures } \\
\hline & & Value & Asymp. Std. Error ${ }^{a}$ & Approx. $\mathrm{T}^{\mathrm{b}}$ & Approx. Sig. \\
\hline Interval by Interval & Pearson's R & 0.245 & 0.057 & 3.624 & $0.000^{c}$ \\
\hline Ordinal by Ordinal & Spearman Correlation & 0.231 & 0.064 & 3.405 & $0.001^{\mathrm{c}}$ \\
\hline $\mathrm{N}$ of Valid Cases & & 207 & & & \\
\hline \multicolumn{6}{|c|}{ a. Not assuming the null hypothesis. } \\
\hline \multicolumn{6}{|c|}{ b. Using the asymptotic standard error assuming the null hypothesis. } \\
\hline \multicolumn{6}{|c|}{ c. Based on normal approximation. } \\
\hline
\end{tabular}

With regards to the correlation between the four themes/axes of this study.

The first axis: the importance of volunteer work from the point of view of the volunteer; The second axis: the reasons for the existence of the phenomenon of offending behaviors on campus from the point of view generally volunteers; third axis: directing Volunteer efforts of the students, professors and human resources at the university for early detection of offending behavior in the university and establish a mechanism to reduce it; The fourth axis : Reasons for participation and assistance mechanism to detect the offending behavior in the university by those who actually participated

From Table 12, the correlation between the first and second axis is 0.139 indicating a weak relationship between the importance of volunteer work from the point of view of the volunteer and the reasons for the existence of the phenomenon of offending behaviors on campus from the point of view generally volunteers. The Sig. ( 2 tailed) is 0.045 indicating that there is no statistically significant correlation between the two variables. The correlation between the first and third axis and the first and fourth axis is 0.431 and 0.369 respectively, also indicating that there is no correlation between each pair of variables. Of all the variable pairs represented in above table there is only a moderate correlation between the third and fourth axis thus indicating that there is a relationship between the two variables.

Table 12

Correlation between the four themes/axes of this study

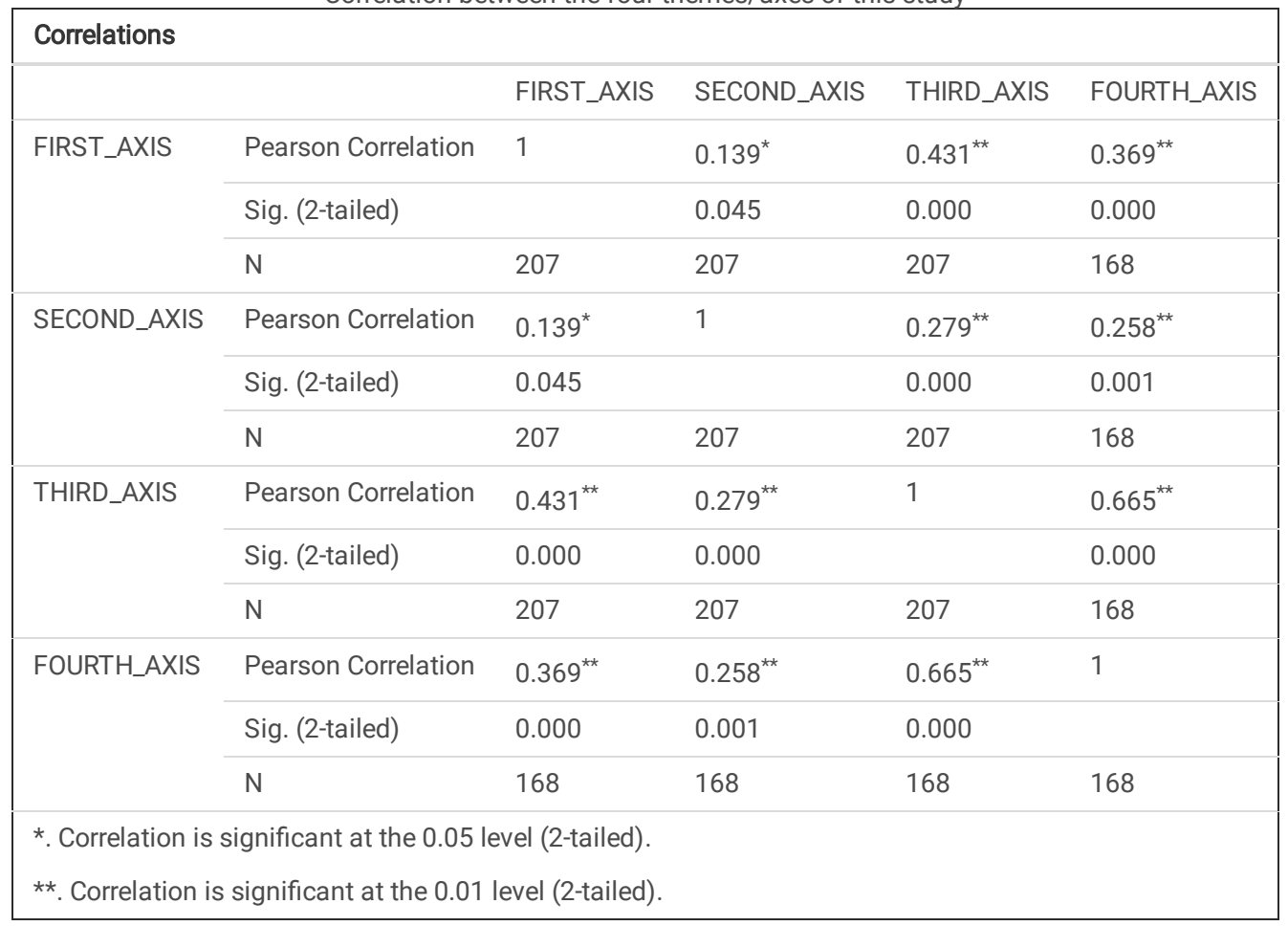

\section{Discussion}

This study was of clearly stated objectives. The features of the respondents were well represented, randomized sampling was also utilized; since the sample profile composed of students, this enable easy access and low cost for data collection. On the other hand, limited number of previous studies related to this topic was reported.

As comparing this study with other previously reported studies, the results of this study showed that youth and young adult form a greater part of volunteering. This is not surprising as the Arab news reported that "the majority of Saudi youth would be more than willing to get involved in volunteer work, 
according to a survey" [32]. Volunteer work span across all work ages, university education level, occupation and marital status. It is revealed that most volunteers prefer volunteering in groups.

Contrary to Sills' classic study on volunteering [33], people not only engage in volunteer work for altruistic motive only but also for other beneficial rewards such as learning new skills and self-development amongst others [34]. A major obstacle to volunteering is the lack of time (48.8\%). Of the unhealthy behavior revealed in this study, attacks on others and properties were the most frequent (17.9\%). This was followed by bullying, insults and verbal abuse (13.5\%). Bullying is obviously among the top list of unhealthy behavior as it takes several forms $[35,36]$ from cyber-bullying to face-to-face bullying, insults and verbal abuses.

At a global scale, there is a rising anticipation that volunteers will cover a bigger responsibility in disaster management and disaster risk diminution in time to come than it has in the past. This is propelled by an increasing global focus on creating "resilience to disasters through a 'bottom-up' process in the form of volunteer initiatives rooted in the community" [19]. Lately, this focus was reemphasized in the 2015-2030 Sendai agenda for Disaster Risk Reduction, arrogated by the United Nation's March 2015 General Assembly [37]. The guideline demanded that "responsibilities be shared" covering all stakeholders and sectors of society and vociferates "an all-of-society engagement and partnership". Also, it renders an extensive catalog of proceedings for "civil society, volunteers, organized voluntary work organizations and community-based organizations" that states should encourage.

Nevertheless, the outlook of volunteering is gradually shifting in the 21 st century in manners that bring significant problems as well as chances for disaster management. Particularly, shifts in the pattern of paid jobs, values and lifestyles, and latest technology, has resulted to a reduction in "traditional", timeconsuming, high dedication volunteering and an increase in more vast, flexible and periodic patterns of volunteering [38]. Considerably, "volunteer strategies in the emergency management sector still depend profoundly on the customary model of volunteering" [39, 40].

Volunteering definitions are changing, alongside the act of volunteering [41, 42]. In Australia, the highest national body lately arrogated a more comprehensive definition: "Volunteering is time willingly given for the common good and without financial gain" [43]. The recent definition cuts across a greatly wider array of budding and less conventional kinds of volunteering juxtaposed to the past, including unofficial and periodic volunteering, group volunteering where member of staff time is contributed, electronic or online volunteering, and activism. This kind of shifts towards more general knowledge of what makes up volunteering in the contemporary perspective are accompanied by the likelihood of higher acknowledgment, legitimacy and protection for the greater variety of volunteering that has constantly taken place in disaster situations. However, greater recognition also brings the prospective for more government mediation, which stressed has tendency to influence the drives and developing behaviors that inspire unofficial volunteering negatively [42].

\section{Conclusions}

The findings reveal that digital volunteering is effectively gaining ground in detection and management of unhealthy behaviors among university students. Much more could be achieved through digital volunteering if more awareness is created and volunteering programs are designed to be more interesting and less time consuming to give more students the opportunity to participate. Based on these facts this study hereby makes the following recommendations: More opportunities should be given to students to participate in volunteering work. There should be proper awareness and orientation about new and existing volunteering work. Students should be encouraged to participate in digital volunteering. Students should be afforded opportunities volunteer outside the university and access the diversity of volunteer opportunities. There should be partnerships among the university, institutions and volunteer associations, which will give another character to female students and develop extracurricular thinking skills for female volunteers, as there are specializations that pay more attention to this aspect, as is the case in the disciplines of social service, psychology and others. Volunteer programs should be design to be less time consuming and more interesting to students while serving the purpose for which there were created.

\section{Declarations}

\section{Abbreviations}

Not applicable.

\section{Funding}

This research was funded by the Deanship of Scientific Research at Princess Nourah bint Abdulrahman University through the Fast-track Research Funding Program.

\section{Acknowledgment:}

The authors would like to thank Princess Nourah bint Abdulrahman University.

\section{Authors' contribution}

All authors were responsible for the initiation, conceptualization and leadership of the guideline development process. AA and SA were responsible for the respondent's survey. RA and SA were responsible for the data statistical analysis and interpretation of results. AA was the primary author of the manuscript. All coauthors were responsible for writing, reviewing, and revising the manuscript for important intellectual content. All authors read and approved the final manuscript.

participated in the study and questioner design, data analysis, drafted the manuscript, and approved it before submission. 
Ethics approval and consent to participate

Ethics approval was obtained for this study from the International Review Board (IRB) in Princess Nourah bint Abdulrahman University.Riyadh, Saudi Arabia with IRB Log Number: 20-0113.The IRB has determined that the proposed project poses no more than minimal risk to the participants. Therefore, the proposal has been deemed exempt from IRB review.Participants were informed that all the information derived from the research tool "the questionnaire" will be dealt with in the strictest confidence and will only be used for scientific research purposes only. Anonymity and confidentiality were explained to participants. Participants were identified with codes to ensure anonymity. Questions that could cause any form of psychological trauma on participants were avoided.

\section{Consent for publication}

Not applicable.

\section{Availability of data and materials}

Any raw data or materials used in the preparation of this manuscript are available upon reasonable request to Dr. Samar Alshawwa (samarzuhair@yahoo.com)

\section{Competing of interests}

The authors declare that they have no competing interests.

\section{References}

[1] Alzoubi H, Alnawaiseh N, Al-Mnayyis AA, Abu- Lubad M, Aqel A, Al-Shagahin H. COVID-19 knowledge, attitude and practice among medical and non-medical university students in Jordan. J Pure Appl Microbiol.2020; 14(1): 17-24. doi: 10.22207/jpam.14.1.04.

[2] Yang H, Bin P, He AJ. Opinions from the epicenter: an online survey of university students in Wuhan amidst the COVID-19 outbreak1. J Chin Gov.2020; 5(2): 234-48. doi: 10.1080/23812346. 2020.1745411

[3] Asaad AM, El-Sokkary RH, Aedh Al, Ali Alzamanan MA, Khalil FO. Exploring knowledge and attitude toward middle east respiratory syndrome-coronavirus (MERS-CoV) among university health colleges' students, Saudi Arabia: a cross-sectional study. Am J Infect Dis.2019; 15(1): 37-43. doi: 10.3844/ajidsp.2019.37.43.

[4] Lyu JC. How young Chinese depend on the media during public health crises? A comparative perspective. Public Relat Rev.2012; 38(5): 799-806. doi: 10.1016/j.pubrev.2012.07.006.

[5] Hassan HM. Knowledge and attitude of Al-Ghad college students towards corona virus infection. Int J Med Res Rev.2016; 4(1): 16-26. doi: 10.17511/ijmrr.2016.i01.003.

[6] DGS - Direç ao-Geral da Saude. COVID-19. [cited 2020 June 3]. Available from: https://covid19.minsaude.pt/.

[7] World Health Organization [WHO]. Coronavirus overview. [cited 2020 June 8]. Available from: https://www.who.int/health-topics/coronavirus\#tab5tab_3.

[8] Arnett JJ. Emerging adulthood: a theory of development from the late teens through the twenties. Am Psychol.2000 May; 55(5): 469-80. doi: 10.1037/0003066X.55.5.469.

[9] U.S. Department of Health and Human Services. Healthy people 2020. [cited 2020 June 8]. Available from: https://www.healthypeople.gov/.

[10] Ellis B. Risky adolescent behavior: an evolutionary perspective. In: Hewlett B, editor. Adolescent identity: evolutionary, cultural and developmental perspectives. Abingdon: Routledge; 2013. 23-9.

[11] Allensworth D, Grizzell J, Stevenson B, Tappe M. Promoting health in schools and universities. In: Fertman C, Allensworth D, editors. Health promotion programs: from theory to practice. San Francisco, CA: Jossey-Bas; 2017. 325-48.

[12] Dooris M, Doherty S. Healthy universities-time for action: a qualitative research study exploring the potential for a national programme. Health Promot Int.2010 Mar; 25(1): 94-106. doi: 10.1093/ heapro/daq015

[13] Stewart-Brown S, Evans J, Patterson J, Petersen S, Doll H, Balding J, Regis D. The health of students in institutes of higher education: an important and neglected public health problem. J Public Health Med. 2000 Dec; 22(4): 492-9. doi: 10.1093/pubmed/22.4.492.

[14] Bruns A, Crisis communication. In: Cunningham S, Turnbull S (eds) The Media and Communications in Australia. Allen and Unwin, Sydney, Australia,2014, pp 351-355

[15] Haworth B, Bruce E. A review of volunteered geographic information for disaster management. Geog Compass. 2015. 9:237-250

[16] Palen L, Liu SB. Citizen communications in crisis: anticipating a future of ICT-supported public participation. Paper presented at the Proceedings of the SIGCHI conference on human factors in computing systems,2007. San Jose, California, USA 
[17] UN-OCHA (2013) Humanitarianism in the network age. UN Office for the Coordination of Humanitarian Affairs (OCHA)

[18] UNV (2015) State of the world's volunteerism: transforming governance. United Nations Volunteers Programme

[19] UNV (2011) State of the world's volunteerism: universal values for global wellbeing. United Nations Volunteers Programme

[20] Reuter C, Heger O, Pipek V. Combining real and virtual volunteers through social media. Paper presented at the ISCRAM, 10th international conference on information systems for crisis response and management2013, Baden-Baden, Germany

[21] Waldman S, Kaminska K, Science D-CfS. Connecting emergency management organizations with digitally enabled emergent volunteering: literature review and best practices. Defence Research and Development Canada,2015. DRDC-RDDC-2015-R271

[22] Meier P. Crisis mapping in action: how open source software and global volunteer networks are changing the world, one map at a time.J Map Geog Libraries2012, 8:89-100

[23] Zook M, Graham M, Shelton T, Gorman S (2010) Volunteered geographic information and crowdsourcing disaster relief: a case study of the Haitian earthquake. World Med Health Policy2010, 2:7-33

[24] Bruns A, Burgess J. Crisis communication in natural disasters: The Queensland floods and Christchurch earthquakes. In: Weller K, Bruns A, Burgess J, Mahrt M, Puschmann C (eds) Twitter and society 2013, vol 89. Peter Lang, New York, pp 373-384

[25] Qin L, Knol MJ, and Corpeleijn E. Does physical activity modify the risk of obesity for type 2 diabetes: a review of epidemiological data. Eur J Epidemio/2010, 25(1):5-12.

[26] Grøntved A., and Hu F.B. Television viewing and risk of type 2 diabetes, cardiovascular disease, and all-cause mortality: a metaanalysis. JAMA2011;305(23):2448-55.

[27] Poortinga W. The prevalence and clustering of four major lifestyle risk factors in an English adult population. Prev, Med.2007, 44: 124-128.

[28] Danaei G, Ding EL, and Mozaffarian D. The preventable causes of death in the United States: comparative risk assessment of dietary, lifestyle, and metabolic risk factors. PLoS Med. 2009, 6(4):e1000058.

[29] Lee, C.B. Adolescent substance use. Funded by: Legacy Conrad N. Hilton Foundation Carnegie Corporation of New York Michael Alan Rosen Foundation, 2013.

[30] Das P, and Horton R. Rethinking our approach to physical activity. The Lancet, 2012, 380(9838):189- 90.

[31] Costanzo S, Di Castelnuovo A, and Donati MB. Alcohol consumption and mortality in patients with cardiovascular disease: a meta-analysis. J Am CollCardiol; 2010, 55(13):1339-1347.

[32] SPA. Majority of Saudi youth 'highly interested' in volunteer work. https://www.arabnews.com/node/1595326/saudi-arabia , 2019.

[33] Sills, D.L. The Volunteers; Means and Ends in a National Organization, Glencoe. The Free Press, 1957.

[34] Gidron, B. Volunteer Work and Its Reward. Volunteer administration, 1978. vol 11:3.

[35] Cowie, H. \& Myers, C. A. What we know about bullying among university students. In H. Cowie \& C. A. Myers (Eds.), Bullying Among University Students. 2016. (pp. 3-14). London: Routledge

[36] Cowie, H \& Myers, C. A. (Eds.) Bullying Among University Students London: Routledge. Retrieved on 20 th July 2016.

from:http://www.routledge.com/books/details/9781138809260/.

[37] UNISDR. Sendai Framework for Disaster Risk Reduction 2015-2030. United Nations Office for Disaster Risk Reduction,2015, Geneva

[38] Hustinx L, Lammertyn F. Collective and reflexive styles of volunteering: a sociological modernization perspective. Voluntas, 2003, 14:167-187

[39] Commonwealth of Australia. National emergency management volunteer action plan. AttorneyGeneral's Department, 2012, Canberra

[40] McLennan J, Birch A. A potential crisis in wildfire emergency response capability? Australia's volunteer firefighters. Glob Environ Change Part B Environ Hazards, 2005, 6:101-107

[41] Hustinx L, Cnaan RA, Handy F. Navigating theories of volunteering: a hybrid map for a complex phenomenon. J Theory Soc Behav, 2010, 40:410-434

[42] Whittaker J, McLennan B, Handmer J. A review of informal volunteerism in emergencies and disasters: definition, opportunities and challenges. Int $J$ Disaster Risk Reduct,2015, 13:358-368

[43] Volunteering Australia Project: the review of the definition of volunteering. Volunteering Australia, Canberra, 2015.

\section{Figures}




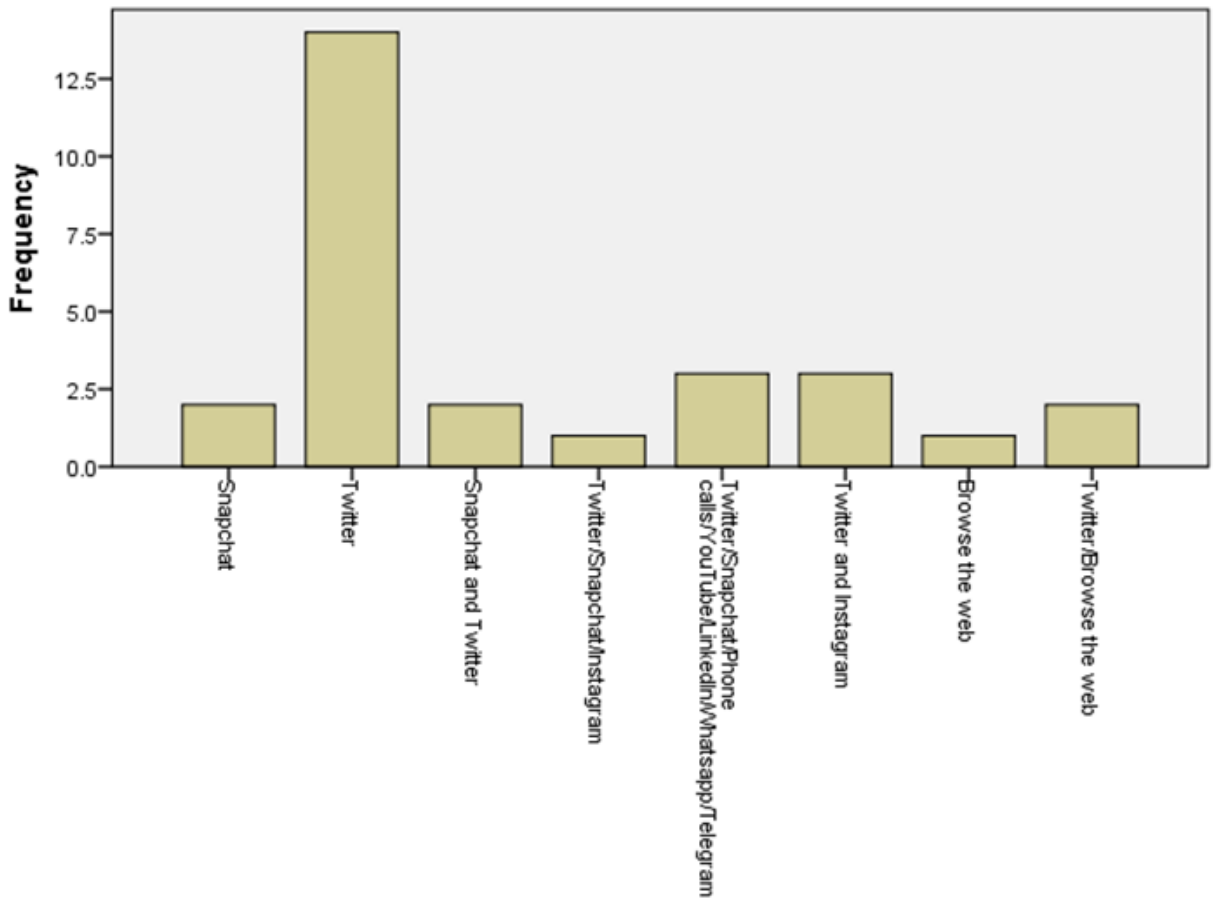

Figure 1

The most widely used methods of communication

\section{Supplementary Files}

This is a list of supplementary files associated with this preprint. Click to download.

- APPENDIX.docx

- arabicquestionnair.pdf

- translatedquestionnairtoenglish.docx 